\title{
Material Availability: A Study of Academic Library Performance
}

\section{Anne C. Ciliberti, Mary F. Casserly, Judith L. Hegg, and Eugene S. Mitchell}

This article reports the findings of a study modeled after Saracevic, Shaw, and Kantor's efforts to identify and quantify the causes of users' failures to identify and locate library materials. The researchers analyzed patron-reported and librarian-observed subject and known-item searches and found an overall success rate of only 54 percent. The problems that led to the 46 percent failure rate were analyzed by source and type of failure, and subjective observations concerning problems encountered by patrons were recorded. Recommendations are made for reducing $l i-$ brary malfunctions and circulation, patron, and acquisition errors.

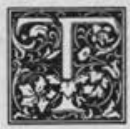

his article reports the findings of an empirical self-study undertaken at the William Paterson College Library during the fall semester, 1985. The college is a statesupported New Jersey institution awarding baccalaureate and master's degrees. It enrolls 7,000 full-time students and employs a teaching faculty of 350 full-time professors. The library, with a professional staff of 20 , contains approximately 300,000 items of print and nonprint material.

The primary purpose of the study was to determine what needed to be done to improve library services. Several important ancillary benefits were anticipated; these included involving staff, particularly those new to the organization, in aspects of the library (and perhaps the college) that were unfamiliar to them and intro- ducing them to the techniques and complexities of evaluating library operations. The potential for a positive political impact, particularly in terms of funding, was also noted. A steering committee comprised of four staff members planned the study, analyzed the data, and prepared the following report. All staff, however, were involved in various aspects of the actual data collection.

Four criteria were used to select a type of self-study that would (1) identify the impact of library weaknesses on users, (2) evaluate functions used by patrons, (3) be feasible, and (4) serve as a management tool, not as an academic exercise.

The selection of a self-study model followed an intensive review of the advantages and disadvantages associated with various library research methodologies. User surveys, document availability tests,

Anne C. Ciliberti and Eugene S. Mitchell are Associate Directors, and Judith L. Hegg is Head of Collection Development at the Sarah Byrd Askew Library, William Paterson College, Wayne, New Jersey 07470. Mary S. Casserly is Head of Collection Development at Fogler Library, University of Maine, Orono, Maine 04469. 
and catalog use studies were all examined and judged against the four selection criteria. From this review it became clear that a shelf availability study developed by Paul Kantor and described in an article by Saracevic, Shaw, and Kantor offered the most advantages. ${ }^{1}$

This instrument provides a measure of performance for a library's acquisitions program, circulation policies, internal operations, and users' capabilities. A branching analysis, used to calculate probabilities, requires that the outcome of each sequential step in the search process be placed into one of several independent categories representing the obstacles to a successful search that must be overcome. In known-item searches, for example, the Kantor model suggests four steps:

1. Has the library acquired the desired title?

2. If acquired, is it in circulation?

3. If not in circulation, is it available on the shelf?

4. If available on the shelf, can the user retrieve it successfully?

According to the branching technique, the proportion of searches that overcomes each of these obstacles represents the probability of success for a category. When multiplied together, these individual success probabilities determine the overall probability of availability.

The Kantor evaluation model was modified by Ciliberti for use at William Paterson College. ${ }^{2}$ The principal modifications were an expansion of the steps or branches involved in known-item searches and the addition of a parallel series of branches involved in the successful completion of subject searches. These branches, represented in figures 1 and 2, are defined below.

\section{ACQUISITION ERROR}

Acquisition errors occur only in knownitem searches when the desired material is not a part of the library's collection or is not fully represented in the card catalog.

\section{APPROPRIATE TITLE ERROR}

Appropriate title errors occur only in subject searches when patrons fail to select call numbers for titles found in the catalog or when, after examination of selected titles, patrons fail to borrow (or use

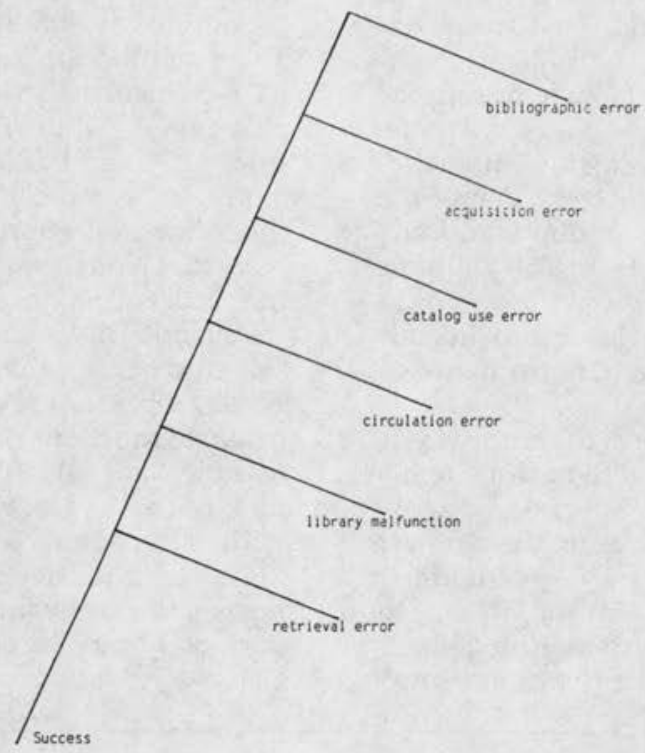

FIGURE 1

Branching Analysis of Known-Item Searches 


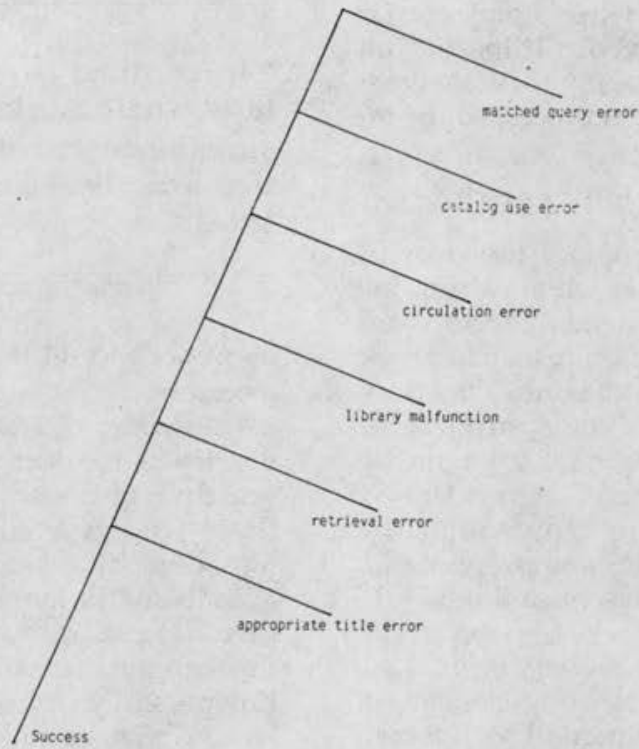

FIGURE 2

Branching Analysis for Subject Searches

in the library) materials found on the shelf. These errors occur when patrons choose not to consult items found on their topics because the material has already been read, is written in the wrong language, is too old or too new, is not at the correct reading level, or is in some other way unsuitable to the information need at hand. All such decisions and judgments are made by the patron; the researcher can only infer from patron actions and note that particular titles were in some way deemed inappropriate.

\section{BIBLIOGRAPHIC ERROR}

Bibliographic errors occur only in known-item searches when the desired material is not found by the patron because the bibliographic clue or citation (either remembered or written) is incorrect and the document can be verified from another source and is correctly represented in the card catalog.

\section{CATALOG USE ERROR}

Catalog use errors occur in either known-item or subject searches when the desired material is not found by the patron as a result of one of the following situations:

1. No call number was identified, and the book had been acquired.

2. An incorrect or incomplete call number was identified.

3. Special location symbols, such as Folio or Ref., printed adjacent to the call number, were not noted.

\section{CIRCULATION ERROR}

Circulation errors occur in either known-item or subject searches when the desired material cannot be found by the patron for one of the following reasons:

1. Item is located on a "hold" shelf waiting to be charged out.

2 . Item has been borrowed for use outside the library and record of the loan transaction is available.

\section{LIBRARY MALFUNCTION ERROR}

Library malfunction errors occur in either known-item or subject searches when the desired material cannot be found by the patron due to shortcomings in the policies or routines of the library or its staff. 
Shortcomings occur when items are (1) missing; (2) misshelved; (3) located on sorting shelves; (4) waiting to be shelved; (5) being recataloged, reprocessed, or repaired.

\section{MATCHED QUERY ERROR}

Errors in matching query terms occur only in subject searches when patrons fail to discover a subject heading in the card catalog that partially or fully matches their query terms. Matching failures may be of two kinds, however. Type A errors occur when no match can be made from the initial query to a Library of Congress subject heading and, therefore, represent patron errors: failing to find the appropriate Library of Congress subject heading.

Type B errors occur when no match can be made from the initial query term to the appropriate Library of Congress subject heading because the library does not own books on that subject; such errors, therefore, represent library acquisition failures.

\section{RETRIEVAL ERROR}

Retrieval errors occur in either knownitem or subject searches when the desired material cannot be found by the patron despite the fact that the correct and complete call number has been noted and the book is in its proper shelf location.

\section{RELATED LITERATURE}

The historical antecedents of shelf availability research are diverse. The beginnings of performance measurement research have been traced to the 1930 s by Ciliberti. $^{3}$ Mansbridge ${ }^{4}$ also cites an example of availability research from 1934. It was not until the 1960 s and 1970 s, however, that strong interest in performance measurement began. During those years many seminal investigations were undertaken, including work by Meier, ${ }^{5}$ Rzasa and Baker, ${ }^{6}$ and Hamburg, Ramist, and Bommer?

Whereas the early studies often endeavored to assess library service in its broadest sense, later research was aimed at evaluating intralibrary document delivery. Within this subfield of study two strains of empirical investigations developed: docu-

\begin{abstract}
"In contrast to document delivery tests, shelf availability studies measure the degree of accessibility for titles actually sought by library patrons."
\end{abstract}

ment delivery tests and shelf availability research.

The works of DeProspo, Altman, and Beasley ${ }^{8}$ and of Orr and others ${ }^{9}$ are representative of document delivery tests. In these studies availability was typically measured by determining the degree of availability for items listed in a bibliography. These citations were obtained through a variety of methods. In the DeProspo study, for example, the citations were drawn randomly from editions of American Book Publishing Record, while they were culled from a broad range of recently published biomedical literature in the Orr study.

In contrast to document delivery tests, shelf availability studies measure the degree of accessibility for titles actually sought by library patrons. In this manner, such variables as the competition for highdemand titles are viewed realistically, rather than in the artificial structure of document delivery testing.

The research presented here is a true shelf availability study and follows the basic methodology first proposed by Kantor $^{10}$ and by Saracevic, ${ }^{11}$ as described later in the article. As such, this study complements an impressive group of studies in which the Kantor design was used; this group includes a longitudinal investigation conducted at Case Western Reserve University. ${ }^{12}$ Several other examples include work by Whitlatch and Kieffer, ${ }^{13}$ Wulff, ${ }^{14}$ Smith and Granade, ${ }^{15}$ Palais, ${ }^{16}$ Kochtanek, ${ }^{17}$ Radford, ${ }^{18}$ Ciliberti, ${ }^{19}$ and Ferl and Robinson. ${ }^{20}$ It is important to note that the research reported here differs from all of those studies except the Ciliberti work, ${ }^{21}$ in that it investigates availability rates for subject as well as knownitem searches. 


\section{METHODOLOGY}

\section{Background}

During the summer of 1984 the Steering Committee discussed how and when library users would be surveyed for selfstudy purposes. Because it was to be based on the outcome of card catalog searches, it was agreed that the self-study would rely on data obtained from a randomly selected group of catalog users distributed throughout the day and week in the same proportion as all users of the card catalog.

Towards this end, a preliminary study of card catalog use was planned and implemented throughout the fall semester. During each weekday hour, library staff observed and recorded each use of the card catalog in half-hour intervals; weekend observations were not economically feasible.

Decisions on the sample size, variables to be observed, and methods of observation were made by the Steering Committee during the summer of 1985 . It chose to follow the cell-size method developed by Galtung for calculating sample sizes. ${ }^{22}$ A sample size of 600 observations was used, and half-hour periods by day of week and week of semester were selected randomly.

A second issue addressed by the committee pertained to the methods of observation to be used for collecting data from the 600 card catalog users. Previous research relied mainly on patron self-reports for data collection. In recent research, Ciliberti ${ }^{23}$ studied library performance on the basis of data collected through both patron self-report and librarian observation. After reviewing the Ciliberti study, which found that self-reported data showed significantly higher levels of library success than data collected by librarian observation, the committee elected to use both methods. Specifically, it agreed to collect data from 600 randomly selected users, by distributing survey forms on which they could record their search successes and failures (self-reported measurement), and from 40 randomly selected users by directly observing their search efforts and recording their successes and failures (ob- served measurement).

The smaller set of librarian observations would serve as a check on the accuracy of the patron self-reports. At the conclusion of the study, the measures derived from the two samples would be compared to determine if the findings differed.

Patron self-report forms were distributed daily between 8 a.m. and 10 p.m., excluding weekends. Written scripts and directions to the staff on how to survey patrons were distributed and reviewed at a staff meeting. Distribution schedules were also generated and sent to staff throughout the semester. Data collectors were instructed to request cooperation from the first patron they observed approaching the card catalog during their assigned half-hour interval. Patrons agreeing to participate were given work sheets upon which to record the titles and/or call numbers of the materials they desired and were asked to return them as they exited. If the first person declined to cooperate, the data collector approached another catalog user.

The librarian observations were made by committee members, who accompanied participating patrons during their consultation of the card catalog and subsequent search of the book stacks.

\section{DATA COLLECTION AND RETURN RATES}

Data collection began the first day of the fall 1985 semester and continued throughout it. Rates of distribution and return were closely monitored by the committee, and steps were taken to insure that these rates remained acceptable.

In addition to conducting the librarian observations of patron searches, the committee was also responsible for analyzing the self-reported data. Each day, members of the committee collected the self-reports that had been returned in the preceding twenty-four hours and randomly selected one title for analysis. If this title had not been found or used, the cause of the failure was determined. This required verifying the call number, subject heading, or bibliographic reference; checking the card catalog; searching the book stacks and 


\section{November 1987}

"... some patrons who had indicated that they were conducting known-item searches had in fact conducted subject searches and vice versa."

sorting shelves; and examining the circulation files and reserve book shelves.

Thirty-four observations were completed, and 401 self-reports were received. The intention to observe forty library patrons was not met, either because of researcher error (the data collector missed the collection time) or because no patrons willing to participate in the study approached the card catalog during the appointed half-hour interval. Likewise, the committee intended to gather self-reports from 600 patrons, but only 560 were distributed for the same reasons. Of the forms distributed, however, 401 were returned and usable, an overall return rate of 72 percent.

\section{RESULTS}

\section{Types of Searches Conducted and Academic Status of Catalog Users}

The data indicate that 53 percent of the patrons who completed self-reports conducted known-item searches and 47 percent, subject searches. The breakdown of librarian-observed, known-item, and subject searches was slightly different, but a chi-square test indicated that this difference is not significant at the .95 level of confidence.

The process of determining which were

TABLE 1

subject and which known-item searches was not as straightforward as had been anticipated. Despite the fact that patrons were asked whether they were looking for materials by author, title, or subject and were given the appropriate form, it was apparent from examining these forms that some patrons who had indicated that they were conducting known-item searches had in fact conducted subject searches and vice versa. As a result, six unsuccessful searches recorded on subject forms were counted as known-item searches, and five unsuccessful searches recorded on known-item forms were counted as subject searches.

As would be expected at a predominantly undergraduate institution, the majority of the participants were undergraduates. This group conducted 69 percent of the total searches observed and 66 percent and 73 percent, respectively, of all knownitem and subject searches (see table 1). Graduate students, the second largest group of subjects, conducted 15 percent of the total searches. While undergraduates carried out an equal number of knownitem and subject searches, graduate students conducted significantly more known-item than subject searches. These findings support Palmer ${ }^{24}$ and Tagliacozzo and Kochen, ${ }^{25}$ who found that the propensity for conducting known-item searches increases with educational level. It should also be observed that the faculty constituted the smallest category of users ( 3 percent).

\section{Analysis of Success Rates}

The overall success rate for the 401 selfreported searches was 54 percent- 215 pa-

ANALYSIS OF TYPE OF SEARCH BY ACADEMIC STATUS

\begin{tabular}{lrrr}
\hline \hline Academic & & Type of Search & \\
Status & Known-Item & \multicolumn{1}{c}{ Subject } & Total \\
\hline Undergraduate & $139(66 \%)$ & $139(73 \%)$ & $278(69 \%)$ \\
Graduate & $40(19 \%)$ & $22(12 \%)$ & $62(15 \%)$ \\
Faculty & $8(4 \%)$ & $6(3 \%)$ & $14(3 \%)$ \\
Other & $15(7 \%)$ & $14(7 \%)$ & $29(7 \%)$ \\
No Answer & $9(4 \%)$ & $9(5 \%)$ & $18(4 \%)$ \\
$\quad$ Total & $211(100 \%)$ & $190(100 \%)$ & $401(10 \%)$ \\
\hline
\end{tabular}

Note: Due to rounding, columns do not total $100 \%$. 
TABLE 2

ANALYSIS OF SUCCESS IN KNOWN-ITEM AND SUBJECT SEARCHES BY METHOD OF DATA COLLECTION

\begin{tabular}{lrrr}
\hline \hline $\begin{array}{l}\text { Method of } \\
\text { Data Collection }\end{array}$ & Success & & \multicolumn{1}{c}{ Total } \\
\hline Observed & $8(47 \%)$ & Subject & $17(100 \%)$ \\
Self-reported & $107(50 \%)$ & $9(53 \%)$ & $215(100 \%)$ \\
\hline
\end{tabular}

trons found the material they were seeking. This approximates the overall success rates of similar studies reported in the library literature. ${ }^{26}$

A comparison of the success rates between known-item searchers and subject searchers using both types of data collection methods, is presented in table 2. As previously explained, the data collected by librarian observation was intended to be a check on the success rates derived from the patron self-reports. This check was needed because the Ciliberti study as noted above, indicated that self-reporting resulted in artificially high success rates in both known-item and subject searches.

The data in table 2 fail to support this finding of the Ciliberti study. Chi-square tests indicate that there are no significant differences in performance due to the methods of data collection. Consequently, the self-reported success rates were not artificially high, as had been anticipated.

\section{Analysis of Search Failures: A Macro Look}

Patrons' failures to locate the books being sought can be divided into six categories for both subject and known-item searches. In tables 3 and 4 , these error categories are listed in the order encountered and the success rate at each step of the search process.

Thus, table 3 shows that 5 of the 211 patrons conducting known-item searches had erroneous bibliographic citations. Of the 206 patrons who had correct information, 21 were searching for titles the library had not purchased. Of the 185 who had accurate citations and were looking for books the library owned, 15 were unable to use the card catalog correctly, i.e., to locate the appropriate cards and identify information necessary for finding the books. Another 15 failed to find the books because they were in circulation. At this point, 155 persons were looking for titles that ostensibly should have been on the shelves; however, 40 of them were unsuccessful in locating these books because of some library malfunction, i.e., the books were not where they were supposed to be. Another 8 were unable to retrieve volumes that were shelved in their correct locations. The total failure rate was 49 percent.

When these errors are placed in the order of their relative negative impact on the search process they indicate where the greatest efforts toward future planning should be directed. The success ratio of only 74 percent at the library-malfunction stage of a patron's search should be of first concern, followed by acquisition, circulation, catalog use, retrieval, and bibliographic considerations.

The subject-search errors shown in table 4 are listed in the order patrons encountered them. Twelve of the 190 patrons conducting subject searches were either seeking titles that had not been purchased or were unable to select subject terms that matched their needs, i.e., were unsuccessful in locating a Library of Congress subject heading that would have been used in the card catalog. Of the 178 persons remaining, 11 had difficulty using the card catalog. Either they could not correctly identify the call number, or they left out the location symbol, e.g., Folio or Ref. Twelve of the 167 patrons who successfully reached this point were looking for titles that were subsequently determined to be in circulation and therefore inaccessible.

Twenty-one of the remaining 155 patrons were unable to locate their materials because of a shortcoming in either the policies or procedures of the library that caused the book to be unavailable to them. Examples of library malfunction include 
TABLE 3

KNOWN-ITEM SEARCH PERFORMANCE BY TYPE OF ERROR AND SUCCESS RATIO

\begin{tabular}{lccc}
\hline \hline $\begin{array}{l}\text { Type of } \\
\text { Error }\end{array}$ & $\begin{array}{c}\text { Number of } \\
\text { Errors }\end{array}$ & $\begin{array}{c}\text { Total Patrons } \\
\text { Searching }\end{array}$ & $\begin{array}{c}\text { Success } \\
\text { Ratio }\end{array}$ \\
\hline Bibliographic & 5 & 211 & $98 \%$ \\
Acquisition & 21 & 206 & $90 \%$ \\
Catalog use & 15 & 185 & $92 \%$ \\
Circulation & 15 & 170 & $91 \%$ \\
Library malfunction & 40 & 155 & $74 \%$ \\
Retrieval & 8 & 115 & $93 \%$ \\
\hline
\end{tabular}

Total Errors: 104

Total Known-ltem Searches: 211

\% Errors: $49 \%$

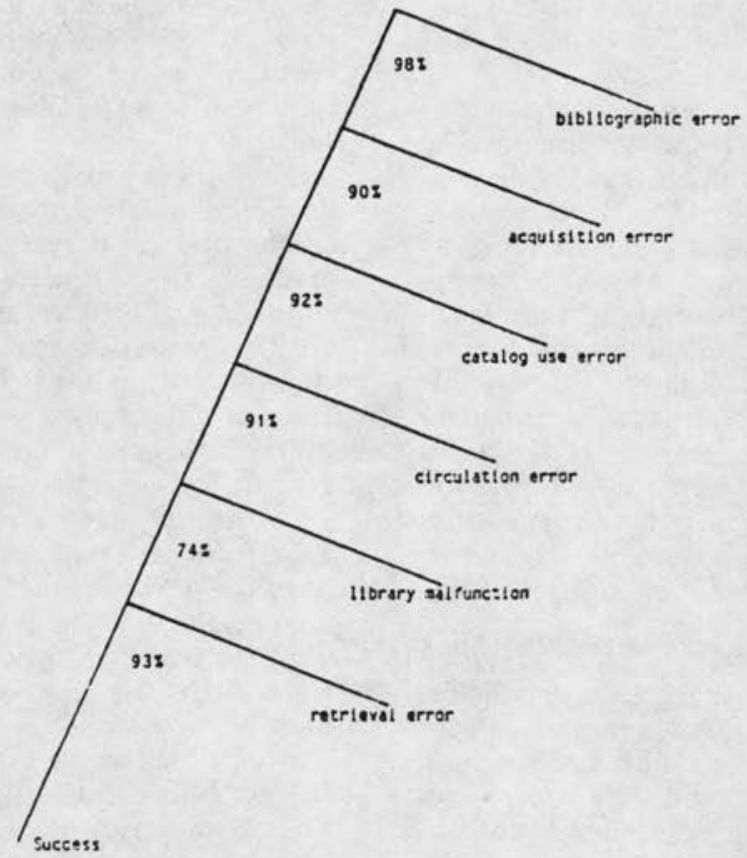

missing books, volumes waiting to be shelved, and materials awaiting cataloging or repair. One hundred thirty-four searchers successfully negotiated these problem categories, but 12 more failures occurred because patrons were unable to find books that were correctly shelved. The sixth type of error, appropriateness, was committed by 14 patrons who found materials on the shelf but decided that they were inappropriate for their needs. The books might have been previously read, too old, too advanced, etc. Thus, only 108 patrons performing subject searches located material appropriate for their needs: 82 were unable to do so, resulting in a failure rate of 43 percent.

It is possible to place the patron errors in the order of their negative impact on the search process: library malfunction is first, followed by appropriateness, retrieval, circulation, matching and acquisition, and catalog use errors.

\section{Analysis of Search Failures: A Micro Look}

The search failures encountered in this study can be further analyzed in three different ways: (1) the origin of the failure- 
TABLE 4

SUBJECT SEARCH PERFORMANCE BY TYPE OF ERROR AND SUCCESS RATIO

\begin{tabular}{lccc}
\hline \hline $\begin{array}{l}\text { Type of } \\
\text { Error }\end{array}$ & $\begin{array}{c}\text { Number of } \\
\text { Errors }\end{array}$ & $\begin{array}{c}\text { Total Patrons } \\
\text { Searching }\end{array}$ & $\begin{array}{c}\text { Success } \\
\text { Ratio }\end{array}$ \\
\hline Matching \& acquisition & 12 & 190 & $94 \%$ \\
Catalog use & 11 & 178 & $94 \%$ \\
Circulation & 12 & 167 & $93 \%$ \\
Library malfunction & 21 & 155 & $87 \%$ \\
Retrieval & 12 & 134 & $91 \%$ \\
Appropriateness & 14 & 122 & $89 \%$ \\
\hline
\end{tabular}

Total Errors: 82

Total Subject Searches: 190

$\%$ Errors: $43 \%$

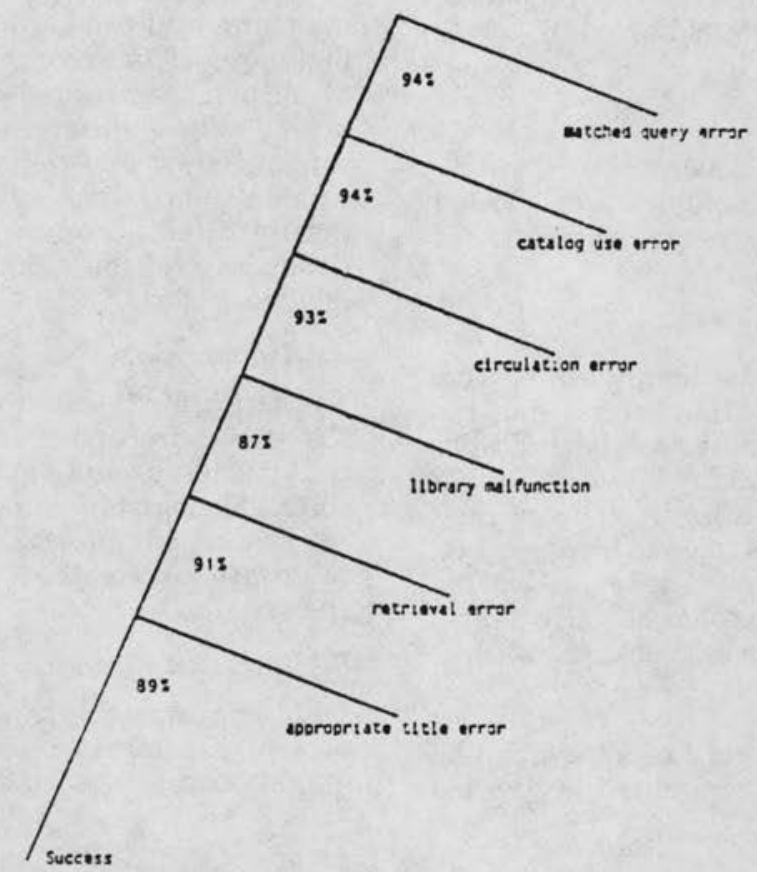

library, patron, and other; (2) the status of the user; and ( 3 ) the longitudinal changes over the course of the semester.

\section{ORIGIN OF FAILURES}

\section{Library Errors}

Sixty-three percent of all search failures can be considered library errors, i.e., shortcomings in library routines. As table 5 indicates, sixty-one ( 56 percent) of these searches failed because the titles sought could not be located on the shelves or in the circulation records. An additional twenty-seven ( 25 percent) of these failures were due to the fact that the desired titles were already on loan, while the remaining twenty-one (19 percent) represent titles desired by patrons but not owned by the library.

\section{Library Malfunction Errors}

These sixty-one errors constituted 56 percent of all library errors. In more than one-half of these cases, patrons consulted the card catalog and found titles that they believed would be useful; however, these titles were unavailable. A closer look at 
"Sixty-three percent of all search failures can be considered library errors, i.e., shortcomings in library routines."

these errors indicates that four were a result of books located on sorting shelves or trucks, two were overdue in circulation, one was on reserve in Lending Services, five were declared lost, and the remaining forty-nine could not be located by library staff

\section{Circulation Errors}

Twenty-seven ( 25 percent) of the failures were the result of titles already being on loan when the patron searched for them.

\section{Acquisition Errors}

Twenty-one of the library errors were considered acquisition errors, i.e., patrons were searching for specific titles which the library did not own. A further analysis of these titles in terms of their suitability for an academic library collection indicated that at least nine, but not more than fifteen, could be fairly judged to have been acquisition errors.

\section{Patron Errors}

More than one-third of all search failures were errors committed by the pa-

trons. Of these, thirty-eight ( 60 percent) failed to use the card catalog correctly or interpret its contents accurately. An additional twenty (32 percent) occurred because patrons were unable to locate a title on the shelf when, in fact, it was there. A small proportion, only five (8 percent), resulted from erroneous bibliographic information brought to the catalog by the patrons.

\section{Matching and Catalog Use Errors}

A total of thirty-eight patrons made matching and catalog-use errors. Note that these failures represented 60 percent of all patron errors-patrons thus appeared to be ineffective users of the card catalog. They experienced difficulty in gaining subject access, in understanding the use of the call number, and in differentiating between the various sections of the divided catalog.

\section{Retrieval Errors}

A surprising twenty ( 32 percent) of all sixty-three errors observed were made by card catalog users who, though having correct bibliographic information and correct card catalog information, were unable to locate books that were correctly shelved.

\section{Bibliographic Errors}

Judging from the small proportion (8 percent) of patrons who committed bibliographic errors, most of them were using

TABLE 5

ORIGINS OF LIBRARY AND PATRON ERRORS

\begin{tabular}{lrrr}
\hline \hline Origin of Error & \multicolumn{3}{c}{ Number (\%) of Errors } \\
\hline & \multicolumn{1}{c}{ Library } & Errors & All Errors* \\
Library errors & No. & $\%$ & $\%$ \\
Malfunction & 61 & 56 & 35 \\
Circulation & 27 & 25 & 16 \\
Acquistion & 21 & 19 & 12 \\
Total & 109 & 100 & All Errors* \\
& Patron & Errors & $\%$ \\
Patron errors & No. & $\%$ & 22 \\
Matching \& catalog use & 38 & 60 & 12 \\
Retrieval & 20 & 32 & 3 \\
Bibliographic & 5 & 8 & 37 \\
Total & 63 & 100 & \\
\hline
\end{tabular}

$* n=172$ 
adequate bibliographic information.

\section{Other Sources of Error}

In addition to library and patron errors, appropriateness errors are a third source of failure in subject searches. Whereas failures in the initial two categories typically represent titles not available at the time of need, appropriateness failures occur when patrons either fail to select call numbers from titles found in the card catalog, or decide not to borrow (or use in the library) the materials found after examining selected titles at the shelf. These decisions are usually made because the patron has already read the material or because, in his or her judgment, the information is too old or too new, not relevant, written in the wrong language or is in some other way not suitable to his or her information need.

In contrast to the large numbers of library and patron errors surveyed, only 8 percent of all failures observed were appropriateness errors. Unfortunately it is not possible from the available data to document the reasons patrons failed to select or use these materials. However, if patrons had had a better understanding of the information contained on the catalog card, it is possible that they would have been better able to distinguish early in their searches which titles were not appropriate to their needs.

\section{Academic Status of User}

Undergraduates conducted 69 percent of all searches surveyed and committed 71 percent of the known-item and 73 percent of the subject errors. In addition, as shown in table 6 , they were responsible for the majority of failures in each error category with the exception of matching errors in subject searches.

A chi-square test was used to determine if the number of known-item and subject failures for undergraduates differed significantly from the number for other groups. The test indicated that undergraduates do not differ significantly in their search performance from all others.

While undergraduates were responsible for 71 percent of the known-item search failures, they committed a disproportion-
"While undergraduates were responsible for $71 \%$ of the known-item search failures, they committed a disproportionately large percentage (93\%) of the catalog use errors."

ately large percentage ( 93 percent) of the catalog use errors. In the subject search category, where they were responsible for 73 percent of the failures, their share of catalog use ( 82 percent), and appropriateness ( 86 percent) errors was again high. They also fell victim to a disproportionately high number of circulation errors.

Graduate students and faculty committed relatively fewer catalog use errors than did undergraduates. The data indicate that the faculty more frequently encountered acquisition failures than other types of failures, while graduate students were more likely to commit matching errors.

\section{Longitudinal Changes}

All patron and library errors were analyzed to determine if there was a significant difference in performance between the first and second half of the semester. Two statistically significant findings should be noted.

Circulation errors increased from the first to the second half of the semester. Circulation failures represented 7 percent of all subject search failures in the first half of the semester and 18 percent during the second half. For known-item searches the failures increased from 2 percent to 22 percent. The most obvious reason for this increase in failure rates is that the chance that an item, particularly a specific known-item, will be in circulation increases as the semester progresses.

While circulation errors increased during the semester, catalog use errors decreased. Catalog use errors represented 21 percent of all subject search errors during the first half of the semester and 10 percent during the second half. For knownitem searches the corresponding statistics are 22 percent and 9 percent, respectively. The decrease in catalog use errors may be the result of increased sophistication 
TABLE 6

KNOWN-ITEM AND SUBJECT SEARCH FAILURES BY ACADEMIC STATUS

\begin{tabular}{|c|c|c|c|c|c|c|}
\hline \multirow{2}{*}{$\begin{array}{l}\text { Type of } \\
\text { Failure }\end{array}$} & \multicolumn{3}{|c|}{ Academic Status } & \multirow[b]{2}{*}{ Other } & \multirow[b]{2}{*}{ No Answer } & \multirow[b]{2}{*}{ Total } \\
\hline & Undergrad & Graduate & Faculty & & & \\
\hline $\begin{array}{l}\text { Bib } \\
\text { Acq } \\
\text { Cat } \\
\text { Circ } \\
\text { Lib mal } \\
\text { Ret }\end{array}$ & $\begin{array}{l}60 \% \\
62 \% \\
93 \% \\
67 \% \\
73 \% \\
63 \%\end{array}$ & $\begin{array}{c}20 \% \\
14 \% \\
0 \\
13 \% \\
10 \% \\
38 \%\end{array}$ & $\begin{array}{c}\text { Known-Item } \\
0 \\
14 \% \\
0 \\
7 \% \\
3 \% \\
0\end{array}$ & $\begin{array}{c}20 \% \\
10 \% \\
0 \\
7 \% \\
8 \% \\
0\end{array}$ & $\begin{array}{l}0 \\
0 \\
7 \% \\
7 \% \\
8 \% \\
0\end{array}$ & $\begin{array}{l}100 \% \\
100 \% \\
100 \% \\
100 \% \\
100 \% \\
100 \%\end{array}$ \\
\hline $\begin{array}{l}\text { Match } \\
\text { Appro } \\
\text { Cat use } \\
\text { Circ } \\
\text { Lib mal } \\
\text { Ret }\end{array}$ & $\begin{array}{l}25 \% \\
85 \% \\
82 \% \\
83 \% \\
76 \% \\
83 \% \\
\end{array}$ & $\begin{array}{c}42 \% \\
7 \% \\
0 \\
0 \\
10 \% \\
8 \% \\
\end{array}$ & $\begin{array}{c}\text { Subject } \\
0 \\
0 \\
9 \\
8 \% \\
5 \% \\
0 \\
\end{array}$ & $\begin{array}{l}0 \\
7 \% \\
9 \% \\
8 \% \\
5 \% \\
8 \% \\
\end{array}$ & $\begin{array}{l}33 \% \\
0 \\
0 \\
0 \\
5 \% \\
0 \\
\end{array}$ & $\begin{array}{l}100 \% \\
100 \% \\
100 \% \\
100 \% \\
100 \% \\
100 \% \\
\end{array}$ \\
\hline
\end{tabular}

Key: $\quad$ Bib $=$ Bibliographic

Acq $=$ Acquisition

Cat $=$ Cataloging

Circ $=$ Circulation

Ret $=$ Retrieval

Match $=$ Matching

Cat use $=$ Catalog use

Lib mal $=$ Library malfunction

Appro $=$ Appropriate

Note: Due to rounding, all rows do not total $100 \%$.

among patrons, exposure to bibliographic instruction, more experience in using the library, or a greater willingness to ask for help from reference librarians.

\section{SUBJECTIVE OBSERVATIONS}

In the course of observing patron searches, several unanticipated patterns of user behavior were noted. Although these subjective impressions cannot be quantified or measured, they provide important information regarding user behavior and performance.

- Patron cooperation was excellent, even though the process of being watched as one searched may have impinged upon patron behavior and privacy.

- Many patrons did not bring writing materials with them to the catalog. It is possible, therefore, that the retrieval rate of the patrons who were observed by librarians was higher than it might have been because patrons were given a form on which to note call numbers and other pertinent information.

- Some patrons lacked persistence when they did not find their materials on the shelves. Nor did they seem to be aware of additional assistance available to them such as reference help, interlibrary loan, and traces.

- The divided card catalog was the source of many problems. Patrons wasted time looking for the correct section; some never did use the appropriate file.

- The name section of the card catalog provided further difficulties for patrons who searched for authors who were either prolific or who were the subject of many critical works, such as Shakespeare. Patrons failed to examine either the preceding or succeeding drawer when each contained appropriate entries.

- Patrons also failed to note the significance of location symbols such as Ref. and Folio.

\footnotetext{
"None of the observed patrons used the Library of Congress Subject Headings even though its use was discussed in bibliographic instruction classes and a copy was prominently displayed at the catalog."
} 
- None of the observed patrons used the Library of Congress Subject Headings even though its use was discussed in bibliographic instruction classes and a copy was prominently displayed at the cata$\log$.

- Many patrons were not able to follow the range identifiers on the stack ends or the arrangement of books in call number order on the shelves. Some titles were not found because they were very thin and their classification numbers were not visible to the patrons.

- Few, if any patrons, checked the sorting area.

- During the process of following up on materials not found by patrons, it became clear that certain idiosyncracies in OCLC records and those of the library's automated circulation system were not universally understood by staff.

\section{RECOMMENDATIONS}

Although the study indicated the success rates of the card catalog users at the William Paterson College Library were similar to those reported in comparable studies at other institutions, the committee members believed them to be unacceptably low. Therefore, an extensive list of recommendations was submitted to the library administration. Those that addressed library malfunctions, the largest cause of patron failure, were given priority. Among the recommendations for improving this area of library operations were initiation of inventory and regularization of shelf-reading programs. Recommendations for remedying circulation, patron and acquisition errors included improving signage, purchasing duplicate copies of high demand items, and incorporating discussions of patron retrieval and card catalog use problems into bibliographic instruction classes.

\section{CONCLUSIONS}

It is apparent that a library's policy decisions, organizational structure, and physical plant idiosyncracies influence patron success rates. At the William Paterson College Library these peculiarities included a building design and window placement that almost invited theft, a long period between inventories, and staff shortages that precluded sending overdue notices.

Although this study was designed to be an in-depth examination of patrons' search successes and failures in a single library, the authors believe that analysis of these findings and the local circumstances that influenced them have implications for library administrators in other academic settings. These implications are presented as suggestions for those who are interested in improving the likelihood that their library patrons will find the materials they need.

An initial step is to consider the impact of lost and stolen materials on patron success. The ease with which materials can be taken from the library without being checked out can be assessed and past policies on replacements and overdue materials studied. The development of an appropriate and realistic inventory program, changes in the physical plant, and/or the installation of an electronic detection system are some methods of ameliorating the situation.

Another factor that may affect patron search success is signage. Directional signs that have become "invisible" to staff members who "see" them all the time may be woefully inadequate. An assessment of signage by an outside party may help improve patron access to materials.

This study has some additional implications for those involved in the design or selection of on-line public access catalogs. In order to minimize catalog use errors library planners should endeavor to design or select on-line systems with selfexplanatory screen displays. Patron confusion and errors resulting from location abbreviations would be reduced if locations within the library (e.g., Ref., Doc, etc.) were clearly spelled out. Further, library jargon need not be incorporated into these systems. Classification numbers, for example, could be labeled "location numbers" or "shelf location numbers" rather than "call numbers."

In addition, administrators may want to emphasize the inclusion of status information (i.e., whether a title is in circulation, at the bindery, on the shelf, etc.) in their 
evaluations of public access systems. Errors stemming from patron failure to find materials on the shelf might be reduced if patrons searched more tenaciously. It seems reasonable to assume that if patrons knew that the material they want should be on the shelf their resolve to find it would be strengthened, and the likelihood that they would continue their searches by availing themselves of trace services offered by the library's circulation department would be increased.

Finally, it is clear that a self-study such as the one described in this report requires a substantial investment of staff time and effort. However, this report also indicates that the rewards for this investment can be the collection of data which accurately reflect patron success and failure in obtaining needed library materials. Further, when the study is properly designed, the sample carefully drawn, and the return rate high, such an effort may enable library administrators to identify and measure the relative magnitude of the barriers to patron success.

\section{REFERENCES}

1. T. Saracevic, W. M. Shaw, and P. B. Kantor, "Causes and Dynamics of User Frustration in an Academic Library," College and Research Libraries 38:7-18 (Jan. 1977).

2. A. C. Ciliberti, "The Development and Methodological Study of an Instrument for Measuring Material Availability in Libraries" (Ph.D. diss., Rutgers Univ., 1985).

3. Ibid.

4. J. Mansbridge, "Availability Studies in Libraries," Library and Information Science Review 8:299-314 (Oct.-Dec. 1986).

5. R. L. Meier, "Efficiency Criteria for the Operation of Large Libraries," Library Quarterly 31:215-34 (July 1961).

6. P. V. Rzasa and N. R. Baker, "Measures of Effectiveness for a University Library," Journal of the American Society for Information Science 23:248-53 (July-Aug. 1972).

7. M. Hamburg, L. E. Ramist, and M. R. Bommer, "Library Objectives and Performance Measures and Their Use in Decision Making," Library Quarterly 42:107-28 (Jan. 1982).

8. E. R. DeProspo, E. Altman, and K. E. Beasley, Performance Measures for Public Libraries (Chicago: American Library Assn., 1973).

9. R. H. Orr and others, "Development of Methodological Tools for Planning and Managing Library Services: II. Measuring a Library's Capability for Providing Documents," Bulletin of the Medical Library Association 56:241-67 (July 1968).

10. P. B. Kantor, "Availability Analysis," Journal of the American Society for Information Science 27:311-19 (Sept.-Oct. 1976).

11. Saracevic, "Causes and Dynamics of User Frustration."

12. W. M. Shaw, Jr., "Longitudinal Studies of Book Availability," in Library Effectiveness: A State of the Art, ed. N. K. Kaske and W. G. Jones. (Chicago: American Library Assn., 1980), 338-49.

13. J. B. Whitlatch and K. Kieffer, "Service at San Jose State University: Survey of Document Availability," Journal of Academic Librarianship 4:196-99 (Sept. 1978).

14. Y. W. Wulff, "Book Availability in the University of Minnesota Bio-Medical Library," Bulletin of the Medical Library Association 66:349-50 (July 1978).

15. R. H. Smith and W. Granade, "User and Library Failures in an Undergraduate Library," College \& Research Libraries 39:467-73 (Nov. 1978).

16. E. S. Palais, "Availability Analysis Report," Association of Research Libraries SPEC Kit 71:73-82 (Feb. 1981).

17. T. R. Kochtanek, "User Satisfaction in the Hugh Stevens College Library," (Arlington, Va.: ERIC Document Reproduction Service, 1978), microfiche ED 190164.

18. N. A. Radford, "Failure in the Library-A Case Study," Library Quarterly 53:328-39 (July 1983).

19. Ciliberti, "The Development and Methodological Study."

20. T. E. Ferl and M. G. Robinson, "Book Availability at the University of California, Santa Cruz," College \& Research Libraries 47:501-8 (Sept. 1986). 
21. Ciliberti, "The Development and Methodological Study."

22. J. Galtung, Theory and Methods of Social Research (New York: Columbia Univ. Pr., 1967).

23. Ciliberti, "The Development and Methodological Study.'

24. R. P. Palmer, Computerizing the Card Catalog in the University Library (Littleton, Colo.: Libraries Unlimited, 1972).

25. R. Tagliacozzo and M. Kochen, "Information-Seeking Behavior of Catalog Users," Information Storage and Retrieval 6:363-81 (Dec. 1970).

26. Shaw, "Longitudinal Studies of Book Availability." 